\title{
La biografía del P. Diego de Alfaro escrita por el P. Diego de Boroa y la defensa de su martirio
}

The biography of Fr. Diego de Alfaro written by Fr. Diego de Boroa and the defense of his martyrdom

Carlos A. Page*

\section{Aclaraciones iniciales}

Continuando con la edición de las obras inéditas del P. Diego de Boroa que se refieren al género biográfico (Page, 2016, Page 2017), e incluso su propia autobiografía (Lovay, 2016) presentamos en esta oportunidad un caso singular en cuanto que se trata de la biografía de una persona que además de conocer y trabajar con el P. Boroa, es un texto que lo exhibe como una defensa al martirio, en una muerte producida junto a los indios con quienes salió a combatir a los bandeirantes que asolaron las reducciones en sus inicios. Defensa y justificación de la toma de las armas por parte de los religiosos.

La bibliografía sobre el P. Diego de Alfaro es bastante completa. Lo es desde los primeros impresos, como el del jesuita belga Alegambe (1657, pp. 531-533) quien a raíz del texto que presentamos del P. Boroa y la opinión de muchos eruditos, escribió que para considerarlo mártir debería esperarse la decisión pontificia, como también acuerda desde el Paraguay el P. Del Techo en 1673 (2005, p. 638). A su vez el P. Nieremberg (1647, pp. 411-416), le dedicó largas páginas, pues fueron imborrables sus recuerdos, al haber convivido con el joven Diego en la Casa de Probación de Villagarcía de Campos (Valladolid), remarcando en su escrito la presencia y el sermón del P. Boroa en sus honras e incluso transcribiendo una elogiosa carta que el P. José Oreggi le envió al P. Boroa sobre su muerte y virtudes. Los tres autores siguen el obituario de la Carta Anua de

\footnotetext{
${ }^{*}$ Investigador del CONICET con sede en el CIECS-UNC (Centro de investigaciones y Estudios sobre Cultura y Sociedad de la Universidad Nacional de Córdoba). Email: capage1@ hotmail.com
} 
1643 del P. Zurbano (Maeder, 1984, p. 146) y cartas del P. Boroa, más sus aportes o dudosos agregados. A ellos debemos sumar la obra de Tanner (1675, pp. 502504) quien además de biografiarlo en 1675, recurre al artista alemán Melchior Küsel, quien representa su muerte en una ilustrativa estampa (Fig. 1).

Un reconocimiento al manuscrito que presentamos lo escribió el propio $\mathrm{P}$. Zurbano en la Carta Anua mencionada, donde después de desplegar sus virtudes, señala: "Merece este Padre la gran veneración que le tributaban sus compañeros y en especial el Padre Diego de Boroa" (Maeder, 1984, p. 149). ¿Se referiría al documento que aquí transcribimos o al sermón que el P. Boroa, como provincial, ofreció en su entierro, donde dijo que había que considerarlo mártir?. Aparentemente el tema del martirio lo sugirió el P. Oreggi en la carta citada, igualmente los propios indígenas, en sus honras, lo coro-

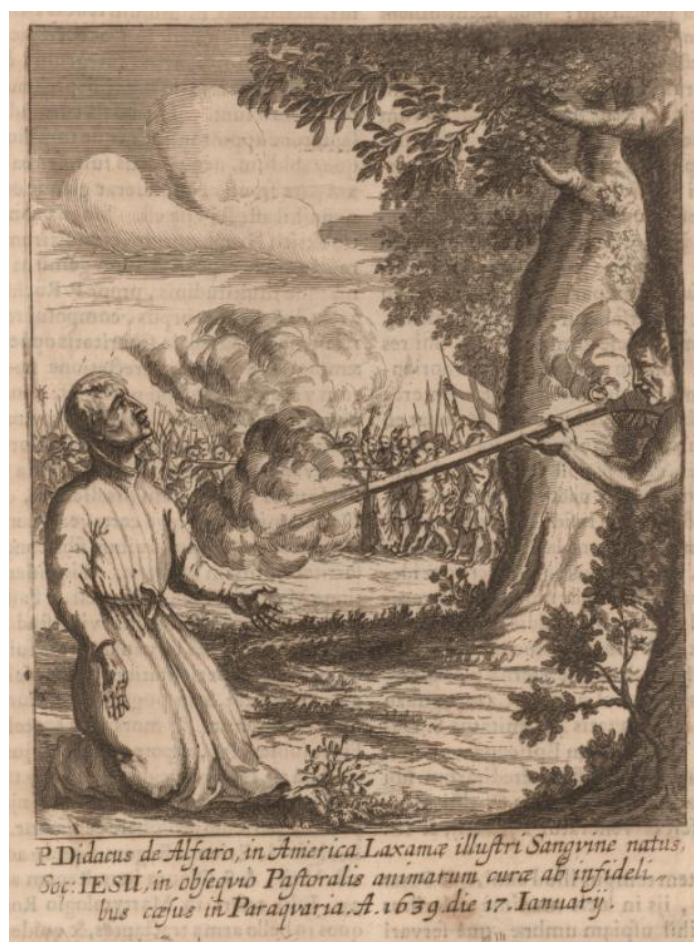

Fig. 1 El martirio en la representación del grabador alemán Melchior Küsel publicado en el libro de Tanner. naron como mártir (De Techo, 2005, p. 637). También es justo señalar que el P. Boroa describió el suceso a varios personajes, desde el general Vitelleschi (presente documento) hasta al rey, como veremos enseguida.

Las biografías sobre el P. Alfaro continuaron reescribiéndose a lo largo del tiempo, llegando por ejemplo a las precisiones del P. Storni (1980, p. 6), más detallado Pérez Alonso (2001, p. 75), pero también el análisis de este documento en particular, tratado recientemente por Redden $(2012,2016)$.

El P. Aflaro nació en Panamá en 1596, llevando el nombre de pila de su abuelo, siendo hijo del famoso redactor de las Ordenanzas que llevan su nombre, licenciado Francisco de Alfaro; destinado primero a Panamá en 1594 como fiscal de su Audiencia y cinco años después a la de Charcas como oidor, siendo nombrado por su presidente, visitador general de las gobernaciones de Tucumán y Río de la Plata. El joven Diego tuvo sus primeros estudios en Lima y posteriormente en Salamanca. No se conoce el nombre de su madre, mientras que sabemos que su padre se volvió a contraer matrimonio en 1613 con Francisca de Sande Paniagua con quien tuvo dos hijas, siendo la cuñada de don Juan de Solórzano y Pereyra.

Ingresó a la Compañía de Jesús de la provincia de Castilla en mayo de 1614 y una vez cumplido su noviciado se embarcó a América, llegando a Buenos Aires el 15 de febrero de 1617 en la expedición del P. Juan de Viana. Concluyó sus estudios de Filosofía y Teología en el Colegio Máximo de la provincia, de donde por un tiempo fue profesor de Filosofía (1623-1625), y luego fue trasladado a las misiones, después de insistentes pedidos al provincial Mastrilli Durán. Quizás su vocación nació a partir que el mismo P. Boroa, en oportunidad de celebrase la cuarta Congregación Provincial, llevó guaraníes músicos a Córdoba para ofrecer a sus compañeros una idea de las acti- 
vidades del Paraguay, con lo que quedaron todos sorprendidos, especialmente el P. Diego (Maeder, 1984, p. 148).

Concluida la Congregación y de regreso a las misiones, los PP. llevaron consigo al joven Diego, quien fue destinado al pueblo de Concepción como compañero de Roque González, fundador del mismo y que luego lo reemplazó (Leonhardt, 1929, p. 362365). Allí fue donde aprendió la lengua y la cultura guaraní, dedicando el resto de su vida a la evangelización del Paraguay. Su cuarto voto lo profesó en Asunción el 19 de marzo de 1632, año en que lo designaron comisario del Santo Oficio en Lima. Como tal dictó varios autos, con referencia a los estragos causados por la bandeira de André Fernandes ${ }^{1}$ y sus amenazas de excomunión a los portugueses de San Pablo (Cortesão, 1969, pp. 163, 170). También por ese tiempo fue nombrado rector del colegio (1631-1635), pero siguió en las misiones, fundando en 1633 la reducción de Natividad de la Virgen de Araricá en el Tape, pueblo trasladado en 1638 por los ataques paulistas que adoptó el nombre de Apóstoles (Furlong, 1962, p. 153). Luego y por decisión del general Vitelleschi fue superior de las misiones de guaraníes del Paraná y Uruguay (1637-1639) en reemplazo del P. Boroa, cuando organizó la defensa armada contra los bandeirantes, con la ayuda de los indígenas y un destacamento de soldados españoles que debían perseguir a los paulistas para rescatar a los prisioneros que iban camino a Brasil. A los fines de solicitar ayuda a las autoridades españolas por los ataques bandeirantes, el provincial $\mathrm{P}$. Boroa, encomendó al P. Alfaro que se hiciera cargo con las autoridades del Perú para que tratara el tema con la Audiencia y el virrey, a lo que el P. Alfaro derivó en el P. Simón Mascetta. Mientras que el P. Boroa envió al P. Ruiz de Montoya a Europa para que insistiera ante la corte, con la posibilidad que lo acompañe el P. Alfaro (Leonhardt, 1929, p. 634).

Luego de una batalla donde venccieron los guaraníes, un portugués escondido en una choza le disparó en la frente. Su cuerpo fue llevado a Concepción, siendo sepultado del lado de la epístola en el altar mayor, junto a los mártires rioplatenses. El lugar de su asesinato fue en Caazapá-guazú (Rio Grande do Sul) el 17 de enero de 1639, en tiempos que su padre era miembro del Consejo de Indias en España y había dejado América hacía ya una década.

Su cuerpo fue llevado en los hombros de los indios, a lo largo de unas 30 leguas, hasta la iglesia de Concepción donde fue sepultado (Maeder, 1984, p. 146) con la presencia del P. Boroa que, como dijimos, era en ese momento provincial del Paraguay (1634-1640).

A los pocos meses el P. Boroa dio cuenta al rey Felipe IV, como lo había hecho en varias oportunidades, de los estragos que cometían los portugueses de San Pablo y Santos hacia las reducciones y ciudades españolas, causando miles de muertes. Lo hacía no solo como provincial, sino como testigo ocular, detallando los acontecimientos con precisión, incluso la muerte del P. Alfaro y la reacción de los indios que lo acompañaron quienes "se arrojaron como leones y mataron nuebe de ellos y muchos de sus Tupis, quitandoles la presa que tenian, de mas de dois mil cautivos" de las reducciones, además

\footnotetext{
${ }^{1}$ Fernandes (c.1578-1649) era uno de los principales bandeirantes de la época quien formó el poblado de Santana de Parnaíba. Su primera bandeira la organizó en San Pablo en 1613, participando luego de la arremetida paulista iniciada en 1628 y prolongada hasta 1632. Luego estuvo en la bandeira de Francisco Bueno, que en 1637 atacó el pueblo de Santa Teresa, luego los del Tape y Rio Grande do Sul. Muerto Francisco, se dividieron los hombres entre su hermano y Fernandes, quien envistió contra las reducciones del Tape. Fue derrotado en Caazapamirim en 1638 y retornó a San Pablo, volviendo con Raposo y muriendo en Itatim.
} 
de tomar varios prisioneros con quienes el gobernador fue indiferente y hasta se escaparon algunos. Efectivamente, el gobernador Pedro de Lugo y Navarra, junto con 60 soldados, estuvieron presentes, pero solo observando la batalla que libraba al frente el cacique Nicolás Ñeenguirú, y "sin disparar un arcabuz se volvieron a sus casas" (Cortesão, 1969, pp. 299-302-390-392).

Redden analizó en dos oportunidades el texto del P. Boroa, quien apasionadamente argumenta que un pastor debe defender a su rebaño aunque implique el uso de la violencia. Esta acción la traslada al sacerdote obligado a defender a sus parroquianos. Para ello, el P. Boroa utiliza un cuerpo teórico muy amplio para su tiempo, donde con una serie de ejemplos remotos justifica la agresión en defensa propia. El contexto también ayuda a su argumento ya que los ataques bandeirantes si bien se hacían para cautivar indígenas, terminaban asesinando a la mayoría para lograr un puñado de esclavos. Y la concentración de población en la reducciones les facilitaba su accionar.

De tal modo que la muerte del P. Alfaro fue diferente a la de quienes morían pasivamente, en un largo lamento de piedad a Dios, sino luchando en la batalla (Redden, 2012, p. 22) peleando por la justicia en defensa de los inocentes como soldados de Cristo. Para el P. Boroa la propia violencia del P. Alfaro lo convertía en mártir, y solo su contexto explica tal afirmación.

La carta del P. Boroa que transcribimos, a pesar que aparece una firma con su nombre, estimamos que es una copia, que incluso fue escrita por dos personas distintas. También en tres oportunidades se manifiesta en el texto que el año "pasado de 41", cuando junto a la firma está la fecha de 1644. Pero son solo detalles de un texto desarrollado con marcada erudición pero al mismo tiempo desgarrador a la hora de comprender el sentimiento de otredad, como a su vez amor al hermano.

ARSI, Paraq. 11. Tomo 1, 1600-1695, ff. 263-270. Carta del P. Diego de Boroa dirigida al prepósito general P. Mucio Vitelleschi, 10 de enero de 1644.

\section{Muy Reverendo Padre Nuestro en Christo}

\section{Pax Christi}

Escrivo a Vuestro Padre esta carta o defensorio, sobre la dichosa muerte del Padre Diego de Alfaro por aver hablado deferentemente algunos della poniendo la boca en el mismo Cielo, que tal nombre merece el dichoso y muy Religioso Padre Diego de Alfaro, asi por sus muchas y grandes virtudes, como por su oficcio Apostolico, siendo uno de los Cielos, que con gran gloria del que le crió, enamauit glorian Dei, siendo Predicador della con mucho nombre a los Españoles, y de Yndios Christianos y gentiles muy insigne, viviendo entre ellos con muy grande exemplo de virtud, y muriendo como buen Pastor por la defensa de su rebaño, echando el resto, y tirando la barra con el mayor y mas heroico acto de caridad, como los enseña Christo Señor Nuestro, dando su vida por sus ovejas, por la salvacion de las quales se ofreció voluntariamente en verdadero sacrificio, a la divina Magestad derramando su sangre, y dando su vida por su amor a imitasion del, que siendo Dios lo derramó por ellas. 
Ni disminuye nada su gloria, lo que los emulos della, y de la Compañía oponen procurando escurecerla con decir, que murio de pelotaço ${ }^{2}$, peleando con una escopeta en la mano capitaneando los Yndios, y quanto a aver muerto de un pelotaço es cierto, pero tuvo tiempo de confesarse antes de morir; que tuviese una escopetilla en la mano, tambien es verdad, pero ni estava armado, ni yva capitaneando los Yndios antes bien en el cuerpo del exercito, ni la escopetilla, que llevaba en la mano, si alguna vez la disparó, fue mas que para animar a los Yndios a la defensa natural suya, y de sus mujeres, y hyjos y de sus Yglesias, y de la fée, y buenas costumbres, y pues es cosa llana, como largamente lo pruevan Covarruvias, Lesio, Suarez, Bonacina, y Molina y otros, que es licito, justo, santo matar al que acomete al inocente, defendiendole quando de otra manera no puede librarse, sin incurrir en irregularidad el Clerigo, que lo haze, como prueva Suarez, Gutierrez, Henrig, Bonacina Azor, y otros muchos, y lo prueva del derecho ni cap non in inferenda 23, quaetiuncula $3^{3}$ adonde trae el exemplo de Moyses, que mató al Egiptio, et ex cap. dilecto de sent. excom. lib. 6 lo qual no solo es licito, y justo, sino, que seria obligatorio y pecado mortal dexarlo de hazer pudiendo, todo esto concurrio en el caso presente del Padre Diego de Alfaro, la qual obligacion es mucho mayor en los Parrochos. Pues por raçon de su officio están obligados a defender a sus Parroquianos especialmente quando la tal defensa se ordena al bien espiritual de las almas, como lo tiene Navarro, Bonacina y otros. Porque los Pastores, como muy bien prueba Becano ${ }^{4}$ de fide cap. Q quaetiuncula 7 tenentes exereve omnes illos actus, ex quorum omission fides contemnit, vel obilitas proximis impeditur vel damnum spiritual seguitur. Pues juntarlos en pueblos para que reciban la fee y despues de recibida no defenderlos, cede en desprecio de la fee, y de los, que la predican, y se impide el provecho, que de recebirla fee se pretende, que es su bien espiritual, y salvacion eterna, que como de medio proporcionadissimo depende de su Reduccion a poblaciones, y no dejen diciéndolos en ellas dixeran que los juntamos como ovejas al matadero, y este es el [263] caso presente de la injusta invasion de los Portugueses de San Pablo, y obligacion, que le corre al Pa$d r e$ Diego de Alfaro como Parrocho a su defensa; el qual caso parece, tenia delante el Padre Doctor Molina ${ }^{5}$ tomo 5 disputa 59 n 6 quod veso, adonde diçe al propósito: Nos tenen sua culpa lethali proecepto ebavitatis Dei subvenive, ac nos opponere, quandi honor et gloria Dei te Christi, peviclitatur coram hominibus id eficendo quod profururum ad id speremus. Y en el caso presente yva la honra de Dios, el credito del Evangelio, y salvacion de millares de almas, pues los mesmos Portugueses falsamente han publicado varias vezes aun en Guayra, que los llamamos para entregarles los que vamos reduciendo, y juntando, cosa muy odiosa y de grande escándalo. Para cuyo desengaño fue menester ver a muchos de Nuestros Padres y hermanos derramar su sangre, y hazer otras grandes demostraciones de fidelidad y amor en su defensa, y estas finezas las

\footnotetext{
2 Aclaramos por ciertas confusiones que "pelotazo" es sinónimo de balazo según el diccionario de Esteban de Terreros y Pando (1788, p. 83).

${ }^{3}$ Decreto de Graciano, $2^{\mathrm{a}}$ parte, causa 23 , quaest 3, cap. 5 , Justitiae plenus est, qui patriam bello tuetur a barbaris. Item Ambrosius libro primo de officiis, c. 27: Fortitudo, quae vel in bello tuetur a barbaris patriam, vei domi defenset infirmos vel a latronibus socios, plena iustitiae est. (Está en plenitu de justicia, el que con las armas defiende a su patria de los bárbaros. También Ambrosio en el libro primero de los Oficios c. 27: La bravura con que se defiende la patria de los bárbaros, o se ampara a los débiles en la propia casa, o se protege a los compañeros de los ladrones es cosa plenamente justa) (Freisleben, 1746, Vol. I, col. 783).

${ }^{4}$ Martini Bacanus o Martín Bacan (1563-1624) jesuita flamenco, destacado y polémico teólogo, fue profesor en Wuerzburg, Mainz y Viena, autor de 37 libros.

${ }^{5}$ Luis de Molina (1535-1600) jesuita, profesor de Filosofía en Coimbra y Teología en Évora, luego prolífero escritor que combina la cátedra en Cuenca con sus obras.
} 
hacen los Padres no temerariamente, si no fundados en la doctrina de los Doctores, que enseñan si deve hazer asi. Vatia tomo 3 disputa 1. quaetiuncula 10. qun: 4 asster. 3. Suarez de fide ${ }^{6}$ Dis, 18 , sect. 1. n. 4 los quales dicen, que qualquier está obligado y mucho mas el Parrocho etiam cren vitae peviculo a defender la vida de su próximo, y mucho mas de su Parroquiano, quoties Religio Christiana infamatia et in tali casu (dicen) tenemur proximorum saluti consulere, y es cierto, que en [...] la Religion Christiana, y la fee y Evangelio se infaman con decirles, que les juntan y christianan para entregarlos a la esclavitud y colleras, y a la misma muerte, y esto se desmiente saliendo con ellos alentandolos y ayudandolos en la pelea, y el medio de animarlos con un arma en las manos era muy propircionado lo uno para desengañar los Yncios, lo otro para animar a gente tan cayda como ordinariamente son estos pobres, pues no tienen mas animo y coraje, que el, que les da el Padre, que los tiene a su cargo.

Esta obligación, que tienen los Parrochos de defender sus Parroquianos es tan estrecha, que hablando dellos en particular muchos y gravissimos Doctores dicen, dever hacerlo aun que sea con peligro de su propia vida. Toledo ${ }^{7}$ libro 4 Summa capítulo IX ar 2 dice ctiam cum periculo vita; meae temporalis, puta, si forte inimici (esto es su Parroquiano) insequuntur, quia tempus est belli ${ }^{8}$, que es nuestro caso en el qual si tienen fuerça los exemplos, como la deven tener en confirmar esta doctrina, dexados otros, dos Sumos Pontifices aparte, el uno de los quales con las armas en las manos echó los Franceses del Reyno de Nápoles, por lo qual, como dice Illescas ${ }^{9}$ coronista adquirió y ganó titulo de legitimo Señor del reyno de Napoles y el otro hasta Hostia puerto de Roma ${ }^{10}$, tambien con las armas en persona echó los Turcos del Estado Romano, el año de $1037^{11}$. Leon nono, que fue Ildelbrando monje con ejercito de Alemanes fue a cobros Benevento de los Normandos, de los quales fue preso, pero con honra vuelto a Roma ${ }^{12}$. Y Lessio ${ }^{13}$

\footnotetext{
${ }^{6}$ Se refiere a la obra del filósofo, teólogo y jurista jesuita Francisco Suárez (1548-11617) Lectiones de fide, publicado por el Colegio Romano en 1583.

${ }^{7}$ Francisco de Toledo SJ (Córdoba, 1532 - Roma, 1596) religioso jesuita, teólogo, cardenal y diplomático destacado en la Contrarreforma. Estudió en las universidades de Valencia y Salamanca, ingresando al noviciado de Simancas de la Compañía de Jesús en 1558. Residió en Roma donde varios Papas le confiaron diversas misiones diplomáticas en Austria, Baviera, Polonia y Flandes. Escribió tratados de teología y comentarios sobre Aristóteles (Donnelly, 2001: 724).
}

${ }^{8}$ Citado por Toleti (1600, p. 36).

${ }^{9}$ Se refiere al historiador español Gonzalo de Illescas (1521-1574), quien se licenció y doctoró en cánones en la Universidad de Salamanca. Fue secretario personal de Alonso de Aragón, grande de la Corona de Aragón, y embajador en Venecia. De vuelta a su pueblo, en Dueñas, escribió su Historia Pontifical y Católica publicada su primera parte en 1565 (Gacto, 1992, pp. 23-40).

${ }^{10}$ Ostia Antica fue una ciudad antigua en la costa del mar Tirreno, en el antiguo Latium, Italia, que funcionó como puerto de la antigua Roma y quizás su primera colonia. Estaba ubicada en la boca del río Tíber.

${ }^{11}$ El Imperio selyúcida fue luego el estado turco.

${ }^{12}$ Hildebrando Aldobrandeschi (c.1020-1085) fue sacerdote de la orden de San Benito que alcanzó el pontificado en 1073 con el nombre de Gregorio VII y canonizado en 1726, es decir que no era León IX que fue también Papa unos años antes (1049-1054) y lo tuvo a su servicio como Legado Pontificio. El suceso que relata el P. Boroa se suscitó con el emperador alemán Enrique IV a quien el Papa lo excomulgó, porque nombraba obispos en contra de la prohibición que había al respecto desde la Iglesia. Gregorio no obtuvo las promesas del emperador y no solo lo excomulgó sino que lo depuso como emperador, reconociéndolo como nuevo rey a Rodolfo, duque de Suabia. Esto causo reacción en obispos alemanes y lombardos que apoyaron a Enrique, proclamando nuevo Papa a Clemente III. Marcha con un ejército sobre Roma en 1084, encarcela a Gregorio y corona emperador a Enrique IV. Pero al acudir los normandos en ayuda de Gregorio, saquean e incendian Roma, con lo que el emperador debe abandonar la ciudad. 
lib. 2 de Justicia cap. 9 dubit. 13, dice teneri Parrochos suos Paraecianos defendere etiem cum peticulo vitae ne Pacsamenta ministrari impediantur. Y es cierto, que los Portugueses de S. Pablo u Santos no solamente son impedidos los Yndios, que injustamente captivan, de recibir los Santos Sacramentos, pero de veinte o treinta mil, que ordinariamente captivan de una redada dire por lo menos mas de las tres partes de quatro mueren, los infieles sin Baptismo, y los Christianos sin Confesion, ni otro Sacramento, quitando a muchos las vidas a hierro con inhumana crueldad, y a los demás a fuerza de malos tratamientos dexando los montes y campos [263v] campos sembrados de cuerpos muertos, y aun de los pocos, que escapan a respeto de los muchos que cojen, en llegando al Brasil, si mueren de hambre, de excessivos trabajos y tristeza, de verse captivos en tierra agena, muchos privados de sus mujeres e hijos, y muchas mujeres privadas de sus maridos, hijas y parientes, los padres sin hijos, y los hijos sin padres, sin yglesias y Sacramentos, como los mesmos Portugueses certifican, y esta aprobado ante su Magestad Catolica como consta de su real cedula de 39 y en las enfermedades y muertes destos pobres, que llevan injustamente captivos de nuestras reducciones o otras partes son los de San Pablo tan crueles y inhumanos, que estando esto, me refirio un Padre Nuestro deste Collegio, que los dexan morir como bestias algunos de aquellos hombres, si tal nombre merecen, los que esto hacen, y que muertos los hacen arrastrar a un muladar adonde sin enterrarlos los perros, o puercos se los comen, cavando sus entrañas, y que esto lo podía jurar. Y en tan extrema necesidad como esta nacion Guarany se ve aperreada, acosada y afligida de sus enemigos de San Pablo, Santos, y demas Capitanias. Quilibet tenetur etiam cum vita periculo subvenive proximom extrema necessitate existenti: ita visit in periculo externa damnationis, quia tune obligar praeceptum vanitatis, quod vinicius man david Dominus de próximo suo Ecle 17. como enseña San Agustin libro 1 de doctrina Christiana capítulo 27. Santo Thomas. 22. quaetiuncula 26. ar. 5. ad 3. Et Valentia ibid Bañez et Avag. quos refer et seguitur Padre Didacus Granado ${ }^{14} 22$, contra. 3. Tran. 7 dis. 4. n. 3. Suarez tr. 3 de ibant. dis. 9. sec. 2. n. 2 et de Fide dis. us. se. i. Fillive er. 28. c. 2 et alii, quod refer et sequitur solorcanus de Indianum I uve lib. i. cap. 13. n. 8 y demas de las raçones que trae San Agustin sobre todas ellas lo prueba con la autob. de su Ju. en la i can. c. 3 Per hoc novimus charitatem Dei, quod ille animan suam pro nobis animam posuit, et nos debemus pro fratribus animam ponere ${ }^{15}$, que es lo que hizo el venerable Padre Diego de Alfaro, imitador de la caridad de Christo Señor Nuestro, y de San Juan cuias son estas palabras sobre las quales muy a nuestro propósito nuestro Justiniano ponderando la caridad de Christo Señor Nuestro, con sus mismas palabras Joan is. n. ig. Maiorem hac dilectionem nemo habet ut animam suam ponat quis pro amieis suis ${ }^{16}$ añade, hane chavitatis veluti forman nobis vetinendam praescriptis vo pro proximonim salute cum causa postular, sanguinem fundere, et mortem subire non recusaremus, art igitur Joanes, in cognovimus chantem Dei, quoniam elle

\footnotetext{
Los romanos también reaccionaron y expulsaron a los normandos junto con Gregorio que se retira a Salerno, falleciendo al año siguiente.

${ }^{13}$ Se refiere a la obra De justitia del teólogo y escritor ascético jesuita de origen holandés Leonardo Lessio (1554-1623). Ingresó a la Compañía de Jesús en 1572 como profesor de Filosofía en Douai, luego estudió en Roma Teología con Belarmino y Suárez. El libro citado por el P. Boroa, con unas veinte ediciones solo en el siglo XVII, es considerado una obra maestra que lo ubica como uno de los grandes moralistas de su tiempo (De Smet, 2001, p. 938).

${ }^{14}$ El P. Diego Granado (1571-1632) fue un jesuita profesor de teología que escribió en 8 tomos los Commentarii in Summam Theologiae, publicado en Sevilla-Granada, entre 1623-1633.

15 Juan III-16

${ }^{16}$ Juan XV-13
}

213 Carlos A. Page. La biografía del P. Diego de Alfaro escrita por el P. Boroa... 207-229. 
animam suam pro nobis posuit, et mor callegu, et nos debemus pro fratibus animam ponere y quando obliga la caridad, y ay obligacion de hazer esto, enseñar los Theologos, y según su doctrina en el caso presente al Padre Diego de Alfaro, como se ha provado, y se apoya mas con lo que añade el Padre Justiniano en apoyo de las palabras de San Juan Hoc tamen praetique ad Episcopos et Eulesiasticos Proesules pertinere traditurus esser, charitatem primum ab illo exigit, deinde futuram mortem et mortis genus praedicit, indicans chatitatem ades perfectam esse debere ut mortem non modo non formidet, sed libenti, hilarie animo illam pro salute fidelirum subeat. Tambien en su dichosa muerte imitó este fiel obrero del Señor la caridad de San Pablo en la 2. ad cor. 12. a quienes dixo ego autem libentissime impendar et superimpendar ipse pro animabus vertris. Sobre lo qual San Chrisistomo hom. 18. Quod dicit impendar, insinuantes et, si et ipsam camem juan insumere oporbeat, non param propter vestram salutem, y llena el intento un grave y religioso Doctor diciendo ubi animanom [264] animanom periclitatur salus, cur metreal Pastor sumptibus, quando et vitam pronom insumere deber bonus Pastor y el peligro temporal y eterno, que toda aquella Yglesia del Uruguay y Parana, cultivada por tantos años, por tantos y tan religiosos sacerdotes de la Compañía, y regada y fecundada no solo con el sudor, si no con tanta sangre de Martires tenia y tiene el dia de oy, no ay para que provarlo, pues es cierto e indubitable. Pues dexada a parte la lamentable destruccion de las Provincias del Guayra, en que la Compañía tenia trece o catorce Reducciones muy populosas ya hechas y otras nuevas en disposicion para hacerse sin los pueblos pertenecientes al Ordinario y las ciudades de Villarrica y Guayra, y Xeres, que obligaron estos enemigos a despoblarse y sus comarcas, captivaron y mataron en todos los años pasados mas de docientos mil almas, según consta de las informaciones juridicas hechas en estas Provincias y en el estado del Brasil, y muchos de los testigos Portugueses, que testificaron de vista, presentadas ante el Rey Filipo 4 Nuestro Señor, y sus Consejos de Castilla, y Portugal, y en la junta de ambos Consejos hecha por orden de su Magestad informando como testigos de vista, el administrador de Rio Janeyro, y los Padres Francisco Diaz, y Antonio Ruiz Procuradores generales desta Provincia en aquella corte.

En las Sierras del Vruguay como los mesmos Portugueses confesaron por su boca en la primera agresion hostil, que hicieron a dos de diciembre dia de San Francisco Xavier del año 1636 llevaron por padron el impío Antonio Raposo ${ }^{17}$, y sus sequaces veinte y cinco mil almas de la Reduccion, populo, de Jesus Maria, y de San Christoval, San Joachim, y Santa Ana, y contornos de la Primera del Tebiquari, y en la segunda, quando se llevaron de quajo la Reduccion de Santa Teresa año de 38, y la començada de Santa Ysabel, y gran parte de las antiguas de los Santos Apostoles, y de San Carlos, y otro pedaço de la Provincia de Tebiquari, serian mas de otras tantas sin otros rrobos, que han hecho en las Provincias comarcanas, y pueblos infieles, que estaban para reducirse, que conputado serán mas de cien mil almas, de las quales solo en estas Provincias de la sierra del Vruguay y Pinales, mas de las ochenta mil han muerto a hierro, trabajos, y malos tratamientos sin Sacramentos matando cuerpos y almas no contando doblado numero de muertos y captivos del Guayra, como esta provado ante la Magestad Catolica, llenando los campos, caminos, y chacaras de cuerpos muertos, y los infiernos de

\footnotetext{
${ }^{17}$ El portugués Raposo Tavares (1598-1658), llegó a América en 1618 y cuatro años después se inataló en San Pablo y en 1628 organizó la primera bandeira con 900 colonos y 2000 guerreros tupi, logrando anexar tierras y capturar gran cantidad de indígenas. Esta de 1636 fue su segunda entrada realizada con el objeto de destruir las reducciones jesuíticas. Luego luchó contra los holandeses que habían ocupado la costa norte-oriental de Brasil. En 1648 nuevamente emprendió una nueva bandeira en busca de oro, minerales preciosos y esclavos indígenas. La controvertida figura fue revalorizada por los brasileros quienes levantaron monumentos en su nombre (Ellis, 1970, pp. 23-61).
} 
almas destos pobrecitos, que cayeron en sus manos, y todo lo que ha quedado, estuviera arrasado y consumido el dia de oy, sino fuera por la caridad muy principalmente del Padre Diego de Alfaro, que sudó a fano y trabajo muchos años defendiendo y amparando su rebaño de los lobos carniceros y sangrientos de los Portugueses del Brasil cargando como buen Pastor no una oveja perdida, sino mas de catorce mil, que puso no solo sobre sus ombros, sino sobre su coraçon de la Sierra del Tape al Vruguay y Parana, escapándolos de la rrabia y furor de aquellos leones fieros, que cevados en la presa, y relamiendose en la sangre de los inocentes corderos, no contentos con aver destruydo en su primera y segunda entrada los pueblos y Provincias arriba dichas y obligado con su rabioso furor, y muchedumbre de armas de fuego, con que vinieron del Brasil a retirar las Reducciones o pueblos de los Martyres, y Candelaria, y San Nicolas forzando con sus incursiones por dos veces a consumir el Santissimo Sacramento, que yo avia colocado otras dos con mucha [264v] mucha solemnidad en su Yglesia, que era excelente, echando con ignominia a Dios vino de su casa, como que fuera un Dios de palo, con muerte de muchos, y asolamiento de casas pueblos e Yglesias de aquellas Reducciones. Luego al tener año continuado, que fue el Enero de 39 se bolvieron a açercar hasta la Reduccion de los Apostoles, que ellos avian destruido el año antes haciendo impía y sacrilegante su paliçada de la madera de la Yglesia, trayendo captivos de la Provincia del Caaro en una sola tropa (que otra y la mayor se apartó a la Reduccion tambien por ellos asolada de Santa Teresa, y se escapo) dos mil captivos, y aun no contentos con ellos para que no quedase piante ni mamante en toda la tierra, que no viniese a sus manos, repartidos como tigres en tropas por aquellos pueblos y Reducciones por ellos asoladas por montes, campos y ríos yban captivando de nuevo los Christianos, que avian escapado de sus garras acercandose ya sus espias al Vruguay, pues en las mismas ermitas de los Martyres nos captivaron algunos mozos Christianos de San Nicolas, que llevaron a su Real, que sabido por el Padre Diego de Alfaro movió sus piadosas entrañas a impedirles sus intentos, y atajarlos los pasos, y para que tuviese mejor efecto, y con menos peligro de los Yndios solicitó al Gobernador del Paraguay Don Pedro de Lugo y Navarra ${ }^{18}$, que a la saçon se hallaba visitando el Parana con sesenta soldados a la defensa, que vino en ello aunque con repugnancia y contradicion de los suyos, y lo mostraron bien en la ocasion, pues estando ya a la vista de los enemigos, y lo que es mas ya muerto a sus ojos (como dire despues) el mismo Padre Diego de Alfaro, de quien se profesava el Gobernador grande amigo no pelearon, como devieran y estavan obligados, y ahorrando lançes en mi narracion (como no lastimar a nadie) fueron de mas estorvo que provecho con gran descredito del valor Español, y opinion que del tenian los Yndios, los quales pelearon con animo y valentía en defensa de sus vidas y de sus almas, y de sus mugeres, e hijos de su patria, de sus Yglesias, y de la Fee, que recibieron en ellas, y de la castidad muy especial abominado de las torpezas horribles y bestiales, que avian visto cometer aquella gente sin Dios, sin fee, y sin verguença con ultraje y afrenta de sus mujeres y hijos.

Y no sufriendo el coraçon al solicito Pastor ver en peligro su rebaño, especialmente en un paso muy peligroso de un arroyo, que servia de trinchera al enemigo reçalandose de çelada (como de hecho la avia) se determinó de asistirle aunque que fuese con peligro, adonde avia estado una Reduccion, y ellos avian tenido sus alojamientos ya desamparados yendo con el ejercito no capitaneado (como falsamente dicen los emulos

\footnotetext{
${ }^{18}$ Gobernador del Paraguay entre 1636 y 1641, fue efectivamente enviado a reprimir a los bandeirantes paulistas con un ejército de 60 españoles e indígenas, pero a pesar que los abandonó, como dijimos arriba, los guaraníes vencieron. Fue convocado a España a dar explicaciones, pero falleció en el viaje.
} 
de la verdad, pues este oficio lo hacia Don Nicolas Neênguini ${ }^{19}$ yndio de valor Christiano Cacique de la Concepcion y Capitan general de guerra [265] guerra por los Governadores del Rio de la Plata) sino animando y esforçando los suyos en su habito religioso y clerical, que llevava con palabras rencorosas, y raçones fuertes y eficaces, como lo sabia hacer por su gran capacidad y eloquencia. Pesarosos e impacientes aquellos enemigos de Dios, y de la feé y de aquellos pobres Yndios, exortandose dos dellos, que estaban escondidos uno a otro, como uno destos lo ha confesado, le tiro el compañero que devia de ser mas diestro a puntería a ocho pasos a traicion un arcabuzaço, de que cayó, aunque no muerto (como ya dixe, pues se confesó) pero murio poco despues volando su dichsissima alma al tribunal de Dios Nuestro Señor a presentar su sangre derramada por la defensa de la feé predicada en aquellas Reducciones, y por aquellos pobres, que le avian recebido, y por la fidelidad de los que Nuestro Señor le avia encomendado, por la caridad y amor a sus ovejas, y obligacion precisa de defenderlas en tan estrecha ocasión y obligatorio lançe, impetrandoles del Señor de los Exercitos la Victoria insigne, que en breve alcançaron de los enemigos contra los, que ellos pretendian y esperaban, de su sacrílego hecho, que muerto el Pastor, tenian ya las ovejas por venidas y presas, que califica y realça mas la gloria de la muerte deste buen Pastor, no casual, sino pretendida de propósito con este perverso fin, de que ay testigos en Casa, que se lo oyeron en el Rio de Janeyro, al que incitó al sacrílego matador del Padre confesandolo de suyo sin apremio, ni tormento.

Honrando tambien el honrador de sus fieles siervos Christo Señor Nuestro el cuerpo muerto deste su fiel ministro y Sacerdote con un favor tenido, y con raçon de muchos por milagroso, pues aviendo muerto a los 17 de Enero de dicho año, quando los calores en aquel Clima son vehementisimos, y en todas estas Provincias, pues son los Caniculares, a las ocho, o nueve de la mañana, y siendo cosa natural, como de ordinario sucede a las 24 horas, y aun antes en tiempo de calor oler mal un cuerpo muerto, y mas no teniendo casa, adonde defenderle al fresco del calor, no solo no olio mal aquel dia, pero el siguiente, que lo llevaron a ambos a enterrar a la Reduccion de la Concepcion, que esta mas de 30 leguas le encontro un adre, y el ejercito del Parana, que yva [265v] yva al socorro, y describiéndole el Padre le beso la mano con reverencia como a Superior suyo, y como a Sacerdote Santo muerto por la caridad, y le halló como que estuviera vivo reverenciandole el ejercito piadoso de sus buenos hijos en Christo, y lo que es mas llegando al tercer dia a la Reduccion de la Concepcion le descubrieron con universal llanto de aquel su querido pueblo, y le hallaron sin hinchazon, corrupcion, ni mal olor, solo algo sentida la parte de la frente (que mugullo el valazo con admiracion de todos, y llegando yo alli poco despues, me lo contó el hermano Juan de Cardenas ${ }^{20}$ religioso por su virtud de mucho crédito, que es el que trató y compuso el cuerpo para la sepultura, que fue junto al del Santo Martyr Roque Gonzalez de Santa Cruz, vi qui ni vita dile erunt se, mortis non separaventur.

Esta muerte gloriossima, que por todas partes lo es, y justificada con la doctrina de la sagrada escriptura, y Santos y Doctores arriba dichos, y de otros muchos, que podiamos alegar, han querido escurecer y anullar en primer lugar los Portugueses, que captivos y maniatados entregaron el Capitan y Cacique Don Nicolas y los demás Capi-

\footnotetext{
${ }^{19}$ Nicolás Neenguirú efectivamente era un cacique natural de la región del arroyo Acaraguá. Fue el capitán general del ejército guaraní organizado por compañías, entre los que se destacó también el capitán Ignacio Aviarú. Nicolás era del pueblo de Concepción y venció a la bandeira que estaba al mando de Pascoal Leite Paes (hermano de Fernão Dias Paes) de 300 blancos y 2.000 tupíes en octubre de 1639.

${ }^{20}$ El coadjutor asunseno Juan de Cárdenas (1598-1647) ingresó a la Compañía de Jesús en 1633, falleciendo en la misma reducción de Concepción (Storni, 1980, p. 52).
} 
tanes y Caciques al Gobernador del Paraguay para que los castigase, como el Rey Nuestro Señor manda por dos o tres cedulas suyas, lo qual no hizo y contento con averlos reñido y dicho que un Comisario del Santo Officio de la Inquisicion a cuyas manos avia de morir, sino de los Potugueses de San Pablo, y no hizo castigo ninguno, ni aun del mismo matador con escándalo de los Yndios. Estos pues movidos de su rencor y despecho de verse presos por los Yndios, y otros Españoles del Paraguay movidos de su pasion y malevolencia, y sentimiento de averles estorvado los Padres, que no llevasen los pobres Yndios del Caamo injustamente captivos, pues demás de ser contra Justicia, era contra raçon que fuese cargado de captivos o piezas (que llaman en esta tierra) los que no avian peleado ni desnbainado espada, ni disparado arcabus y tambien se volvieron contra el Padre Diego de Alfaro arnque muerto (cosa impía) y contra los Padres corridos de no aver hecho con gran menoscabo del nombre Español lo que avian hecho y acabado unos [266] pobres Yndios desnudos; y lo que peor es, que sin ocasion ninguna para que este siervo dexo Señor Nuestro de si por el Propheta Odio habuenins me gratis se parezca mas a su Maestro Personas por su estado y Profesion de mas obligaciones, y en quien la ignorancia es mas culpable y la malicia mas agena a buena raçon de su estado, por ignorancia o malicia o por ambas a dos cosas juntas ayan querido poner su inconsiderada lengua en aquel feliz y dichoso sacerdote digno de eterna memoria porque si de qualquier justo dice el Espiritu Santo in memoria aeterna erit iustus, aun mas de lleno le quedara a un justo muerto por su amor.

Ni puede escapar de aver no solo ignorancia, pero malicia a lo que oponen a este venerable Varon, pues si supieran que no solo es licito, pero obligatorio en extrema necesidad de cuerpo y alma al Pastor y Parrocho (como lo era el Padre) pues era Cura universal y Superior de todas las Reducciones y pueblos de aquellas Provincias defender sus ovejas como tengo provado arriba con la raçon y autoridad de tantos y tan insignes Doctores, no condenaran al que con tan santo zelo y tanta caridad cumplió con sus obligaciones aventurando su vida con otros Sacerdotes y Hermanos Coadjutores animando aquella pobre gente, pues es certissimo e indubitable, que sino hicieran los Padres este officio de caridad con sus Parrochianos fueran muertos, o por lo menos captivos, como varias vezes lo han confesado los mismos Portugueses diciendo ya conocemos indios, Padres apartense y verán como los cansamos y vendimos y dicen verdad, de adonde se ve claramente que la libertad y vida de sus Parroquianos pende como de medio unico y necesario de las armas de fuego, y de la asistencia en la guerra de sus Padres y Pastores, que es el caso en que los Doctores dicen que es justo y aun obligatorio al sacerdote no solo exortar si no pelear, y matar para defender al inocente y mas en especial al Parroco para librar su Parroquiano del peligro de cuerpo y alma, y condenacion eterna que es lo que hizo el Padre Diego en quanto al exortar y animar a la pelea aunque no mato a nadie y siendo [266v] y siendo esto asi como lo es, injustamente condenar por mala nuestros rigorosos censores una accion tan justa tan santa y obligatoria, ni el tener el Padre una escopeta en la mano, ni aunque la huviese disparado es reprehensible, pues siendo como es, por lo menos justo, honesto, y meritorio, y segun muchos, como prové obligatorio el pelear el sacerdote, y mas si es Parrocho en el caso dicho, la ves que se avia de pelear y estuvo obligado a hazerlo por sus Parroquianos inocentes, no havia de ser con las manos en el seno sino con armas, sea espada, ó lanza, ó escopeta, porque si es justo el fin, tambien es justo el medio necesario para alcançarles, si no está prohibido, como no lo está este, y es conforme a lo dispuesto L.2. de Jurisdict. Demas de que si huvieran leydo al Cardenal Caietano ${ }^{21}$ sobre la 2.2. quaetiuncula q. a 2. vieran como en

${ }^{21}$ Tomás Cayetano (1469-1534) fue maestro general de los dominicos (1508-1518) y diplomático de la Santa Sede, siendo una de sus misiones la de convencer a Lutero que abandonara su propósito de cisma.

217 Carlos A. Page. La biografía del P. Diego de Alfaro escrita por el P. Boroa... 207-229. 
ocasiones semejantes se puede y se debe disparar arcabuces, y aun bombarda: Cum finis legis sitcom bonus, ae legis squalis bonus slade (Dise este sapientissimo Doctor) ae bonus come tale ae opuale, quod insto bello defensivo servatur, praste bono particular alicuives \& Contesmset vs licite levicus suena bene dirigere bombarda alys nom existestibus, vela lio ali casa manse propia salues patna vel exercitu sine tal auxilio pereunt; seisolu videtur quod licite post its clericus, de detia quod ad hoc teneatus in tal, articulo, propter cande ratione prasertim si eu Infirelibus ajatur. Y dado caso que el Padre Diego de Alfaro huviese disparado la escopeta, fue licito y santo, como lo fue en que Leon y Sumo Pontifice referido arriba en persona fuese en el exercito no tanto por las animas Beneventanas, como por el estado temporal de la Yglesia, que posee hasta el dia de hoy i por lo qual vino a ser preso de los enemigos, si bien con honra tratado, como se devia a la dignidad Pontifical, como se dixo. Pues quanto mayor razon tuvo el Padre Alfaro por las almas y bien espiritual de los Yndios, de favorecer en persona, y defender aun con armas sus ovejas de tan crueles lobos, us saluares son solu patria et exercitu, veru Eulia, fidem, erata, emulta fideliu millia fidem conversa. Refeadiendolos de peores que infieles en una apretura tan grande.

Pero demos, que no hubieran visto a este a semejantes Doctores, sino que la passion ó malicia les huviera dado lugar á leer las historias antiguas ó modernas, ó a informarse no ya de legos o juristas, sino de soldados platicos de Alemania, Flandes, e Italia, lo que en los siglos pasados y en los presentes pasta cada dia en los exercitos del Emperador y nuestros Catholicos Reyes de España, y otros Principes christianos, pues religiosos sacerdotes, y aun Prelados de las sagradas ordenes de Santo Domingo, San Francisco, San Agustin, Carmen, la Merced, y la Compañía se arman y ciñen espadas sobre sus habitos y quando la ocasion lo pide desparan arcabuces defendiendo las partes de las muralles que les reparten los Governadores y Magistrados, de que en este colegio de la Compañía de Jhesus de Cordova y en las mismas missiones ay testigos de vista y los años pasados un Santo Religioso Capuchino, y otro de la Compañía eran de los Principales que endereçavan la artilleria en el exercito Catolico, por ser muy diestros y Religioso fue el que una bombarda mató al Embaxador de Francia, que estaba a lado del Principe de Orange Hereje Holandes, que llevara pliegos, y summanos de papel de casos singulares de nuestros días y refiriera una ilustre hazaña muy celebrada entre los Catolicos, que contra un Hereje hizo peleando un Santo Religioso tenido por tal en el exercito Catolico llamado J. (N.) de Aguirre, [267] de la Orden Serafica y sacara aplaço ya al Papa Julio 2 armado en campo y peleando no ya por la defensa de la fe y de sus ovejas, sino del Estado y dominio Ecclesiastico, que injustamente le usurpavan sacara al Santo Cardenal y Arçobispo de Toledo Don Fray Francisco Ximenes de Cisneros de la Orden Serafica y fundador de la Universidad de Alcala peleando con los Moros de Oran; pero dexadas estos, y otros muchos insignes varones, no puedo dexar de referir algunos casos, y sea el primero del Serenissimo Infante Don Fray Sancho de Aragon hijo del Rey Don Jayme, religioso de la sagrada Orden de la Merced, despues obispo de Toledo, que teniendo juntó exercito y fue a la Andalusia a pelear contra los Moros, para impedirles el passo y la historia de si orden haviendo costado el caso y muerte del Santo Arçobispo, era de estas palabras en la primera parte 1.4. c. 4. Desta muerte, que al fin fue dirigida y ofrecida a defender la fe, y el nombre Christiano, aunque casual, hablan algunos clara y distintamente haciendola martyrio, y el Arçobispo Martyr. Y esto no obstante decir la historia, que esta muerte fue casual, y la del Padre Diego Alfaro no lo

Fue profesor de teología en las universidades de París y Roma, cardenal y arzobispo de Palermo y de Gaeta, su pueblo natal. Varias de sus publicaciones fueron prohibidas y quemadas en Francia. Este texto que se refiere el P. Boroa no lo hemos podido identificar dentro de las seis obras que conocemos. 
fue, sino prevista, y el Padre, que era muy docto, sabia bien lo que podia y decia hazer. Demas de que en Buenos Ayres en una junta de muchas personas doctas, que quatro dellos havian leydo Theologia, se havia determinado lo que assi desperto de los Padres, como de los Yndios se podía y devia haser y este Papel se embió a las Reducciones, y en ellas mismas hizimos otra junta de doze ó quatorze Padres pocos meses antes de su muerte, es que tratamos del peligro grande dela vida, que corrian los que asistian a los Yndios en la guerra justa defensiva que hazian, y nos exortamos y animamos a dar las vidas, teniendo a feliz suerte morir por tan piadosa y justa causa, y como el Padre era Superior de los demás, y corria por su cuenta y direccion la defensa u asistencia, vió su mayor peligro y con aseveracion (sin duda con luz del cielo que le prevenía) dixo a sus compañeros muchas vezes, que havia de morir en tan justa demanda, y assi su muerte y la causa della fue muy conforme a su intencion calidad del verdadero martyrio, como enseña el Padre Gregorio de Valencia, y la interacion del matador, como dixe, se conformó con la del Padre, que fue muerto.

Sigisberto Rey de Nortumbra ${ }^{22}$ de muchas letras y de mayor piedad, como cuenta el Padre Geronimo Plati ${ }^{23}$ hizo una cosa digna de eterna gloria, (que son palabras del Autor), que como se hisiesse religioso y poco despues Pheudas Rey de la Mercia ${ }^{24}$ viniendo con grande exercito sobre Nortumbria, aunque ya era religioso, le suplicaron sus antiguos vasallos los defendiesse y siendo la casa tan pia y santa, salió y se fue a los Reales de los enemigos en su mismo habito religioso a gobernar el exercito muriendo en la batalla, por lo qual, dize Plati, algunos lo cuentan entre los Martyres.

Pero mas á nuestro propósito es el exemplo de Juan Rey de Armenia que dexando a Leon su tío el reino, se entró religioso ${ }^{25}$, y siéndolo sobrevino un grande exercito de Judeos quien no podia resistir el reto, por ser niño, y el Santo religioso abuelo, viendo que aquello era causa de Dios, se vistió las [...] el habito religioso y salió a la batalla y peleó. Y hecha una brava matança echó de sus confines sus enemigos, yendo en el alcanze dellos, que viéndolo Dios assi para premiarle condise el Historiador fue herido y muerto en el alcance, y si la antecedente fue muerte gloriosa, y lenta por martirio, y esta fue tan preciosa en los ojos de Dios y de los hombres, si haver quien las calumniasen porque nolo será lo del Padre Diego de Alfaro? Porque aunque está puesto en opinion el que sale armado al campo encara justa contra los enemigos de la fe ó de la Religion, ó de la virtud fieles ó infieles, sea propia y injustamente martirio, de lo qual trata Santo Thomas in supplem. 3d. ptis. p. 69 a. 6. Muchos y graves doctores espe [267v] cialmente en las insignes Universidades de Lovaina y Duay y entre ellos el doctorsissimo Sylvio $^{26}$ Doctor y catedrático de Theologia duacense tiene que el tal es Martirio y lo prueba

\footnotetext{
${ }^{22}$ Northumbria fue uno de los antiguos reinos anglos formados en Gran Bretaña en 616 y se extinguió en 954.

${ }^{23}$ El P. Piatti (Milán, 1545 - Roma, 1591) era jesuita, connovicio de san Estanislao de Kostka, secretario de la Compañía de Jesús en su casa generalicia de Roma, donde fue maestro de novicios y director espiritual de San Luis Gonzaga. Escribió varias obras del que se destacan De bono status religiosi (1589), sobre la utilidad, dignidad y consuelo de la vida religiosa, traducida a varios idiomas.

${ }^{24}$ Peada gobernó entre c.653 y 656. Hijo de Pybba. Elevó a Mercia a un estado dominante entre los reinos anglosajones. Fue el último gobernante pagano de Mercia, muerto en batalla por Oswiu de Northumbria.

${ }^{25}$ Juan era en realidad Haitón II (1266-1307), monarca del reino armenio de Cilicia. Renunció en dos oportunidades para tomar los votos franciscanos. Lo sucedió León III y ambos dirigieron al ejército armenio en 1305 para derrotar a sus enemigos, pero fueron asesinados por el general mongol Bilarghu.

${ }^{26}$ El nombre de Silvius era Pierre van den Bossche (1534-1571) jesuita admitido en Lovania en 1552 , donde luego enseñó Filosofía y Teología, al igual que en Roma, Florencia, Tivoli, Praga, Ingolsladt, Colonia , etc (Sommervogel, 1896, VII: 1212).
} 
con la autoridad del mismo Doctor Angelico ${ }^{27}$, el qual en la quaetiuncula 2. ad 11 dize que el soldado merece Aureola de mártir, si su pelea referatur ad Christi, refiriendo su pelea al Chronicles vs pote dize el Santo, si rempublicam defendat ab hostium impugnatione qui fidem Christi corrumpere moliuntur, el in tali defensione morte sustineat. Y el Doctor Sylvio ya citado 2.2. quaetiuncula iz. 5. estiende su doctrina a todos aquellos Qui in bello visto rem defendunt amore instia, y si la Yglesia declara muchos dellos por martires, es porque entre los tales ay otros muchos, que en la tal guerra justa pelean por el interes ó estipendio ó por ser sus Confederados, ó por otros fines no onerosos, y como la santa Yglesia procede con tanta madureza y examen, y fuera muy dificultoso discernir los usos de los otros, es la razon, como dize el Doctor Sylvio, de que ordinariamente no los declara por mártires, pero no ha dexado de declarar a algunos aunque no murieron por la fe derechamente, los quales está en el martirologio Romano a 18 de Mayo Eorio, o Henrico Rey de Suecia ${ }^{28}$, que murió peleando con Henrico hijo del Rey de Dania, defendiendo su reyno; y a 29 de julio haze memoria el martirologio Romano llamandole martir de San Olaf ${ }^{29}$, que murió peleando con los de Dania, y le celebra la Yglesia por Martir, y San Bernardo sermones ad milites templis capitulo $\mathrm{j}^{30}$, llama martires a los que morían en la guerra de jerusalen, pues hablando dellos dize Quam heati moriuntos Martyrs in praelio. Y echase de ver que este fue sentimiento común de los Santos, pues eseiendo Chunon Abat segovergense al Venerable Ruperto Abad $^{31}$ sobre este punto, como de cosa asentada en la Yglesia desea del saber la causa Cur Machabdon bellica defensic non minus quan indefensa Martyru patientia in Santa Eulesia ${ }^{32}$ legendo escantando celebretur. A que dexando otras muchas razones muy substanciales, que han movido a muchos graves Doctores a decir que son Martires, los que mueren en la pelea, refiriendo ea ad christum di como dice Santo Thomas, le responde, que la causa desta veneracion dela Yglesia, y de ygualar los Machabros con los Martires fue por haver defendido con sus armas peleando el pueblo escogido de Dios, y los Primogenitores, de adonde havia de nacer Xcristpo Señor Nuestro. Y si vale esta raçon, por haver sido defensores del Pueblo de Dios, pueblo esogido de Dios es el que defendia el Padre Diego de Alfaro, y si vale por haver defendido de la muerte los Primogenitores y Padres de Xcristpo, porque no valdrá por haver defendido los hijos del mismo Xcristpo por la fe, por el Evangelio y Baptismo? De los quales dise el mismo Christiano, que estos tales, que le siguen, y hasen su voluntad, son no solo sus hijos, pero su madre y hermanos. fase meus frater soror cli. Y si algunos de los arriba dichos los llaman los Historiadores martires, y a otros la Yglesia, que es mucho mas, aunque murieron peleando y armados, porque desmerecerá esta honra el Padre Diego de Alfaro, el qual en ninguna manera

\footnotetext{
${ }^{27}$ Se refiere a los escritos sobre las Sentencias del dominico Santo Tomas de Aquino (1224/1225-1274) que siguió de Pedro Lombardi.

${ }^{28}$ Eric IX de Suecia ( 1120-1160) fue venerado como santo durante la Edad Media, pero la Iglesia Católica nunca lo ha canonizado. Su asesinato ocurrió cuando salía de misa de la catedral de Upsala, allí varios hombres lo derribaron de su caballo y lo decapitaron. Fue considerado martirio por su hijo Canuto y seguidores, pero el Papa Alejandro III se negó a reconocer su santidad.

${ }^{29}$ San Olaf de Noruega (995-1030) impulsó el cristianismo en su gobierno, murió mártir en la batalla de Stikkestad convirtiéndose en símbolo de la independencia de Noruega.

${ }^{30}$ Se trata de la obra de San Bernardo Fontaine (1090-1153) "De laude novae militiae ad milites Templi", compuesta entre 1128 y 1136.

${ }^{31}$ Ruperto de Deutz (c.1075-1129) fue monje valón y abad de la ciudad de Deutz, destacándose como teólogo, exégeta y místico. La mayoría de sus escritos no se han conservado, pero sus obras influyeron notablemente en los teólogos del siglo XII.

32 Debe ser Santa Eulalia (292-304) cuyo aterradora muerte, luego de sufrir un martirio espeluznante, lo dejó escrito en el siglo IV Prudencio, uno de los mejores poetas cristianos de la antigüedad.
} 
yva armado, como es testigo todo el exercito, solo con su habito religioso sin pecho, cota ni escupil ${ }^{33}$ ó semejante defensa, que si llevava arma defensiva, casco ó morrion ${ }^{34}$ siquiera de nuevo doblando, como se osa en estas tierras, no le huviera muerto la bala de esa escopeta ni el Padre sabia pelear, ni fue soldado en su vida, criado desde niño en sus estudios, ni la escopetilla, que dixe como dixe, llevava en la mano, le podía servir de defensa, pero si de dar animo a los Yndios ala defensa y su fin, que era el bien común elata ad Chrom ea ad defensie fides, eaveiaru sibi reditaru salute ea totius reip de [roto], que es todo lo que pide Santo Thomas en la q cis y resporsion adsi y mucho mas se halla y verifica en el caso presente. Y si Santo Thomas dice expresamente que si el pelear referatur ad Christum, Aureola osevebitus ae Martyr erit, mas de treinta o quarenta testigos religiosos [268] entre ellos yo, podemos testificar y jurar, que no era otro el fin deste venerable y religioso sacerdote, y que este fin con la propiedad y rigor, que pide el Santo Doctor le movia y le puso en el peligro tan manifiesto dela vida, dándole por amor de Xcristpo Señor Nuestro y defensor de los recién convertidos á Nustra Santa Fe por el credito del Santo Evangelio, defensa de las Yglesias, que havia visto tantas vezes quemadas, y profanadas por los enemigos, y fin a fuer de buen pastor, su fin fue defender dela muerte temporal y eterna el rebaño, que Dios y los Superiores le habían encomendado, como Superior, Padre y verdadero parrocho de todos ellos.

Y si el Doctor Sylvio estiende como vimos, la raçon de martirio alos que en guerra justa defienden larepublica por amor dela justicia, no havrá Doctor estolica ${ }^{35}$ ni universidad alguna que no affirme que esta guerra defensiva que hazen los Yndios de nuestras reducciones, a que los Padres les asisten, sea justissima y por saldada el Papa Vol. 8 y el Rey Nuestro Señor en sus cedulas de 34 y $41^{36}$, y siendo assi, como lo es, claro está, que es virtud y muy grande ayudar y defender en especial el Parrocho a estos pobres en guerra defensiva justa y segun Sylvio es martirio, y lo mismo se prueva con la doctrina de Santo Thomas en el lugar citado ad io, adonde dize que la causa suficiente al martirio no solo es la confession dela fe, sed quavenque alia virtus politica sedinfusa quo fine habeat Christianos, porque con qualquier acto de virtud aliquis Christianos efficitus. Lo mismo dizen el Padre Doctor Manuel de $\operatorname{Sar}^{37}$ y Gregorio de Valencia ${ }^{38}$

\footnotetext{
${ }^{33}$ Se refiere a la correa o cíngulo para sujetar la túnica y el escapulario que, con o sin capuchón para cubrir la cabeza, es una banda que cubre los hombros y pende por delante y por detrás

${ }^{34}$ El morrión era una armadura para la cabeza o casco de los antiguos caballeros y también la infantería.

${ }^{35}$ Estólica, cerbatana, propulsor, lanzadardos o átlatl es un arma de proyección que permite la impulsión de dardos, utilizada en toda América precolombina y por cierto por los guaraníes que llamaban katapohã que era un tubo de takuara o de paxiuva escavado de unos tres metros de largo.

${ }^{36}$ En cuanto a lo relativo de poner a los indígenas convertidos sin armas en "cabeza real", estuvo lejos de resolverse cuando comenzaron las reducciones. Veinte años después el general todavía se mostraba indeciso y solo la Provisión del Virrey del Perú de 1631, confirmada por Cédula Real de Madrid en 1633, decidió esta cuestión vital, confirmando luego lo resuelto varias Cédulas posteriores. E1 21 de Mayo de 1640, Felipe IV firmó una Real Cédula por la que remitía al virrey de Lima el poder otorgar a los misioneros la gracia de armar con bocas de fuego a sus neófitos, si lo creía conveniente. Pero quedó en suspenso ante las representaciones en sentido contrario, lo que le costó trabajo al P. Montoya refutar los argumentos y un trámite burocrático que terminó con la Real Cédula del 21 de noviembre de 1642 que resolvió confirmar la de 1640, es decir dejar el asunto en manos del virrey del Perú (Hernández, 1913, pp. 524-526).

${ }^{37}$ Manuel Sarmiento de Mendoza (ca. 1580-1650), fue un clérigo español, canónigo de catedral de Sevilla, de la primera mitad del siglo XVII, escribió varias obras, entre las que se encuentran sermones alusivos a distintas celebraciones religiosas..

${ }^{38}$ Gregorio de Valencia (1549-1603) fue un teólogo jesuita español, distinguiéndose su trabajo literario por una renovada teología escolástica. Lecciones, temas de controversia y varias apologías y discursos
} 
tomo 3, disputa 5. question 2. punct 1; que dize, definiendo el martirio Martyriu est te domiu quo noste psa pro Deo obita testificatur quis aliqua fidei heribate in seipsa, del un Alipio pio virtus opere relvente y bien se vee lo que reluce y brilla en esta muerte del Padre Diego de Alfaro el fuego de caridad con Dios y con los próximos Padre Diego Granada y otros.

Pues segun el Doctor Angelico y estos graves Doctores es martir el que de la vida por qualquiera virtud, quien la dio por la maior de las virtudes, que es la caridad luz y resplandor de todas las virtudes con el maior acto della, que es dar la vida por sus amigos, esto es por sus parroquianos por sus ovejas por sus hijos en Xcristpo, y por sacar y redemir de cruel captiverio mas de dos mil almas que tenian en su palishada injustamente presos los Portugueses como de hecho se sacaron y pusieron en libertad de cuerpo y alma, pues todos se convirtieron ala fe, que los mas eran infieles y muchos de sus hijos baptize yo poco despues, no obstante, como no obsta, alomenos en sentir muy probable el haver muerto el Padre en el conflicto dela pelea, aunque fuera defendiendose, mucho fundamento ay para poder llamar mártir al Padre Diego de Alfaro, y para entender, que real y verdaderamente lo fue, y que su bendita alma coronada de Aureola de martirio pereció ante el tribunal de Xcristpo Señor Nuestro a alcanzar gracia y mesericordia para aquellos, por cuyo amor tenia derramando su sangre, y le favorece mucho la doctrina de nuestro Eximio Doctor Padre Francisco Suarez en su tomo de defensie fide ${ }^{39}$ libro 6. capitulo 11, probando que no solo hacen martires la confession de la fe, como diximos de Santo Thomas, y el morir por no quebrar algún precepto, sino tambien el morir por alguna causa por la de Dios, y vtil a los próximos. Non enim dize este gran Doctor homo operatas justitiam, quando obedit praecepto sed etiam quoties operatur proptec Christum, \& Dei gloriam, licet tunc non obligatur; ergo qui patitur ne hanc justitiam voluntariam, id est nom necessariam tuncex precepto, Deo autem gratam, \& proximis utilem omittat, re vera propter eander causam, vere occidatur propter causam Religionis, ac subinde est verus Martyr. Palabras notables, adonde es de reparar que dize [Ronneas] sarid [268v] sarid tum es precepto, y que en nuestro caso sienten muchos, que fue necesaria \& obligatoria por ser Parocho; y en las palabras, Des grata \& proximis vsile, que son notables, y muy á mi proposito.

Pero dexo esta qualificacion ala Yglesia, a quien pertenece el declararlo, y contentome con decir lo que nadie puede negar, y auna boca dezen aun los Doctores dela otra sentencia, y aun en caso no tan apretado, como el nuestro de obligacion de pastores, que si los tales no son mártires, que por lo menos su muerte es gloriosissima, de quienes dize Ruperto, Jure nomen celebre possident in Eulesia que sus nombres con justicia y razón son muy celebres en la Yglesia, siendo su muerte preciosissima semejante al martirio, ygual a el en la substancia, aunque le falte la aureola de propio y verdadero martirio, como lo pruevan muchos y granvissimos Doctores y el Padre Francisco Suarez en el tomo citado cuya autoridad sola bastava.

Y si el venerable y Santo Obispo del Brasil Don Marcos de Texeira ${ }^{40}$, según dizen ya electo Arzobispo de Lisboa, fue venerado y tenido por santo en vida y en muerte,

completan su reconocida obra. Acá se refiere a sus Commentarii theologici, aparecidos en 4 volúmenes, impresos en Ingolstadt, entre 1591 y 1597.

${ }^{39}$ De la inmensa obra del jesuita filósofo, teólogo y jurista Francisco Suárez (1548-1617), se refiere en este caso a Defensio fidei catholicae adversus anglicanae sectae, publicada en 1613, por sugerencia del Nuncio en España, a raíz del juramento de fidelidad que Jacobo I de Inglaterra exigía de sus súbditos, refutando la apología del juramento que el Rey había hecho publicar.

40 Teixeira fue diputado del Consejo General e inquisidor del tribunal de Évora, carrera que abandonó para acceder al obispado del Basil. Al ser invadida Bahía por los holandeses (1624-1625) y tomar preso al 
assi por sus muchas virtudes, como muy principalmente por el zelo, que mostró en defender y liberar sus ovejas en la invasion que hizieron los herejes holandeses en la Bahya, saliendo en persona á campaña armado no solo á pelear con los enemigos, sino capitaneando como buen pastor el exercito de sus ovejas, de queselo ocasionó la muerte, echando sangre por la boca molido del peso delas armas; no menos estima y veneracion se deve al Padre Diego de Alfaro, Superior que era de todas aquellas reducciones ó poblaciones, y Comisario del Santo officio dela Inquisicion, pues movido por el mismo fin y motivo de caridad, y defensa de su rebaño salió a campo, ya que no armado, pero animado ala pelea espuesto á dar la vida por los suyos, y derramar su sangre por su amor, como en efecto hizo moviendo no casualmente como dixe arriba, ai de su parte, que yva muy prevenido, ni de parte de quien le mató, que como se dixo, se sabe de testigos fide dignos de boca del que estava a lado del matador del Padre, y le castigó, le apuntasye pareciendole que matando el pastor, tenia cierta la presa de las ovejas, y que su defensa dependía en gran parte del animo que les dava el buen pastor, no con armas, sino palabras, y con su presencia, y por el odio quele cobraron, y le tenían ya delos años pasados por el valor, con que les defendia la presa le derribaron a puntería, como dixe, pudiendola hazer á otros Padres que estaban alli cerca, como en otras ocasiones lo han hecho, apuntandoles de proposito por la ojeriza, que les tienen por ser verdaderos $\mathrm{Pa}$ dres y pastores, hiriendo á muchos en diferentes ocasiones, y amenazandolos aun desde el mismo Brasil de muerte y captiverio, creciendo cada dia mas en rabia y coraje contra el rebaño de Xcristpo y sus pastores, y mucho mas el año pasado de 41 que no contentos conla contradiccion que intentaron hazer la Bula, que en defensa delos Yndios destas provincias, especialmente los reducidos por la Compañia expedió la Santidad del Papa Urbano $8^{41}$, excomulgando y anathematizando alos Portugueses del Brasil, que les hacen guerra injustamente matandoles y capturandolos, mandando debajo delas mismas penas y censuras, que son gravissimas restituyan los Yndios, que han robado a sus naturales, de que furiosos trataron matar en el rio Genero al Padre Francisco Diaz ${ }^{42}$, que solicitava su publicacion, y ya que no loexecutaron, acometieron impacientes nuestro Colegio con tan grande desacato, que amotinandose fueron en odio de la Bula Apostolica contra nuestro colegio dela Compañía de Jhesus, porque los de el estado presente el Padre Visitador, persona gravissima la apoyavan ayudando al Padre Procurador desta Provincia, y con impetu con hachas y machetes [269] rajaron la puerta dela porteria dando muchos golpes y cuchilladas en un Jesus de bronze que estava en medio dela puerta en la exilla, rompiendo y quebrando la clausura religiosa, derribando hasta la segunda puerta, y entrando en la Yglesia, queriendo abalanzarse por las rejas de la capilla mayor apellidando pueblo, y pasando adelante, a no estorvarselo el Governador Salvador Correa de Sa y Bermudez ${ }^{43}$, haciendo en Santos y San Pablo en odio del Papa y

gobernador, asumió el mando de la resistencia el obispo Teixeira quien entró a la ciudad con 1.500 hombres, de los cuales un tercio eran negros. No fue arzobispo de Lisboa.

${ }^{41}$ Se refiere al italiano Maffeo Barberini (1568-1644), Papa entre 1623 y 1644, quien por Bula Pontificia Comissum Nobis del 22 de abril de 1639 prohibió estrictamente la esclavitud de cualquier tipo, entre los indígenas de Paraguay, Brasil y todas las Indias Occidentales. Bula que la consiguió el procurador del Paraguay Francisco Díaz Taño (Bullarium, 1769, pp. 109-110).

${ }^{42}$ Se refiere al P. Francisco Díaz Taño (1593-1677), superior de las misiones (1646-1649 y 1657-1658). En 1631 el P. Ruiz de Montoya le encomendó encontrara ayuda militar contra los bandeirantes en Asunción y Chuquisaca, donde se la negaron. Fue a Europa como procurador en 1637 y consiguió la bula arriba mencionada. Se detuvo en Río de Janeiro para hacer conocer su contenido y al saberse, una multitud atacó el colegio jesuítico, poniendo en peligro la vida de sus ocupantes (Baptista y Carman, 2001, p. 1116).

${ }^{43}$ Nacido en Cádiz, Salvador Correia de Sá y Benevidez (1602-1688), al servicio de Portugal, luchó en 1625 en la mencionada invasión holandesa a Salvador de Bahía. En 1637 fue designado gobernador de la 
de su Bula, de que hablavan como que fueran Herejes, diciendo que si viniera allí, le havian de colgar, por haverle embiado aquella bula, y otras proposiciones mal sonantes, y de los dela Compañia y sus colegios echandolos violentamente dellos, lo que hizieron en Irlanda ó Inglaterra, y tomando con gran furia alarma, se juntaron los soldados de aquellas capitanias, y con numeroso exercito hecho de todos, y de sus falsos tupis y verdaderos captivos de nuestras reducciones, las acometieron el marzo pasado de quarenta y uno, con intento de no dexar rozo ni velloso como dizen, y acabar con todo, especialmente que es ni principal intento, se vaya a Buenos ayres, que por impío y escandaloso recogió el Comisario del Santo officio, en el qual mostravan sus intentos de matar y capturar todos los Padres, si bien seles volvió el sueño al revés, pues con haver echado el resto de su poder, fueron los impíos y descomulgados vencidos afrentosamente de aquellos pobres Yndios desnudos, que muertos muchos hizieron huyr a presta los demas, asistiendoles los Padres sin temor dela muerte ó cautiverio, que todo haze sobresalir la feliz y dichosa muerte del Padre Diego de Alfaro, dadas por gente infiel á Dios a su fe, y a sus yglesias, y rebelde al Cicario de Christo, inobediente a sus bulas y mandatos con desprecios de su santísima y Beatissima Persona, y sus bulas, y proposiciones horribles mas de Calvinistas o Luteranos, que de Catolicos, y finalmente de gente trahidora á su Rey y Señor natural, como son el dia de hoy.

Ni son todos los de la Compañia los que como buenos pastores salen en campo, y arriesgan sus vidas por su rebaño, pues el Ixellentisimo Señor Obispo de Paraguay Don Fray Christoval de Aresti ${ }^{44}$, deseó hallarse como el me dixo varias vezes en una destas orasiones, para mostrar su Santo Zelo, y en fin hallandose y salió en persona al encuentro, porque nole cautivassen sus ovejas con dos clerigos con dos alfanjes o terciados en las manos alos lados para la justa defensa, aunque no llegó al efecto el acontecimiento y pocos meses las que el Ixellentisimo Señor Don Fray Bernardino de Cardenas también obispo del Paraguay ${ }^{45}$, honrando este colegio de Cordova con su presencia, llegando un indiesito de las reducciones que se hallo aquí á besarle la mano, se afervorizó tanto en presencia de muchos, que estavamos presentes, que sirviendo yo á su Señoria de interprete le dixo, y en el á todos sus parientes, que no temiessen y se consolassen que les havia de defender de aquellos enemigos, aunque fuese tomando a un arcabuz al hombro, de que el indio quedó gozoso y todos muy edificados i fue oferta repentina la del Señor obispo pues teniendo noticia cinco meses ha, de que los de San Pablo del Brasil venían a hazer nuevainvasion y con mayor fuerza a nuestras reducciones escrivió

\footnotetext{
capitanía de Río de Janeiro, retomando entre 1658 y 1662, regresando a Portugal como miembro del Consejo de Ultramar.

${ }^{44}$ Cristóbal de Aresti (1570-1638) fue un fraile benedictino, quien procedente de Valladolid fue designado obispo del Paraguay, cargo que ocupó entre 1629 y 1635, fecha esta última que se lo nombó obispo de Buenos Aires. Visitó las misiones y las defendió de los ataques paulistas, organizó el segundo Sínodo de Asunción y en 1632 hizo su visita pastoral al Guayrá en plenos ataques de los bandeirantes. Presenció la destrucción no solo de las reducciones sino que debió ordenar la evacuación de Villarrica antes su destrucción.

45 Bernardino de Cárdenas (1562-1668) fue un franciscano obispo del Paraguay con nombramiento real en 1638, con bula pontificia de 1640. Cárdenas partió para su diócesis antes de recibir la bula, con lo que los jesuitas de Córdoba, en este caso su rector, el P. Diego de Boroa, le respondió que de acuerdo al derecho corriente no podría consagrarlo por falta de la bula. Igual Cárdenas marchó hacia Santiago del Estero para que el obispo de Tucumán lo consagrara. Lo consiguió y partió a Asunción en 1642, visitó las reducciones, informó favorablemente al rey sobre la actividad de los jesuitas. Pero la relación con los jesuitas tomo un giro cuando Cárdenas les solicitó que les regalara una estancia recién adquirida por los ignacianos y como estos se negaron les dio un plazo de ocho días para entregársela. La historia es más compleja y termina con la primera expulsión de los jesuitas de Asunción en 1649, además de tomar el cargo de gobernador.
} 
luego a los Padres le embiasen embarcacion, porque queria yr a pelear en defensa de sus ovejas, como de hecho fue, si bien no havian llegado los enemigos, pero el buen pastor mostró serlo con levantar el cayado contra los lobos, pues no ay pastor tan sufrido, que viendo el cordero en la boca del lobo, no le tire el cayado y aun saque piedras del garron para escaparles de sus garras; y si ala vista de uno se afervorizó y animó tanto el Señor obispo, que será quando vea en aquellas reducciones y poblaciones que están á cargo de los Religiosos de la Orden Serafica, y de la Compañia tantos millares bien doctrinados sin borracheras, pendencias ni escándalos, y que fuera y que hiziera con su santo zelo si viera cortar con inhumana crueldad braços, piernas, y cabeças de Indios con menos lastima, que si fueran bestias? Que sintiera, y que hiziere, si viera arrastrar y apartar el hijo del padre, arrancar la muger del marido, la hija dela madre maniatandolos y capturandolos?, y que hiziere y dixere [269v] viendo ponerlos en prisiones, cadenas y collares de hierro? Y que dixera y hiziera, si viera unos quebrados, otros travessados y heridos y hacinas de cuerpos muertos, como los vió el Padre Diego de Alfaro no una sino muchas vezes y van yo dos en que nos ayudamos ambos con otros padres, que no bastando sepulturas los ahacinamos y amontonamos en una fossa enterrandolos en ellas, que fue en la reduccion de Jesus Maria y San Christobal. Dixera su Illustrisima como tan piadoso y tan docto, sintiendo con muchissimos Padres arriba dichos, que en tal caso peleará gravemente el pastor, que pudiendo no defendiera sus ovejas, aunque fuera tomando las armas, y cargando arcabuz al hombro, como su Señoria dixo, y aun disparandole para salvar no solo al inocente sino al hijo en Xcristpro por su Evangelizacion y Bautismo, (que tales son estos dichos) al Parrochiano, ala oveja e inocente cordero delas gargantas y garras sangrientas de lobos y tigres carniceros, que tales son estos ladrones y robadores, y salteadores no solo de haziendas, pero de hombres christianos e infieles de pueblos y provincias enteras, que han asolado destos profanadores de yglesias, no haziendo en su descargo el ser christianos, pues si lo son, lo son solo en el nombre, y en los hechos y crueldad peones que herejes, Moros, y Gentiles, pues estos como es claro y se ve cada dia, no hazen los desafueros e insultos que estos falsos christianos, y verdaderos enemigos de Xcristpo Señor Nuestro de su Fe y Evangelio cometen sin temor ni verguença, los quales, como dize su Magestad Catholica en dos cedulas suyas del año 1634 y en otra de 1641 fecha en Madrid á 7 de enero despues del alzamiento de Portugal no solo son traidores a su corona, pero infieles á Dios e enmigos de Religion Christiana, y no solo facinerosos, pero la mayor parte dellos christianos nuevos (que son palabras de su Magestad bien informado, porque ellos mismos dizen estas cosas unos de otros) y aun sospechosos de la fe, y como a tales y violadores y profanadores de yglesias, y despreciadores de los Santos Sacramentos, en el especial del Santo matrimonio, encargó a su supremo consejo la Santa Inquisicion y proveyese de remedio y el Santo tribunal declaró por caso de inquisicion el que cometen los de San Pablo y Santos, y mando fuese castigado por tal, y la Santidad del Papa Urbano 8, comoya dixe los de scomulga y anathematiza.

Dixera y sin duda dize el Señor obipso lo que han dicho y dizen las personas mas graves y doctas destos reynos Eclesiasticos, religiosos y seculares, Señor Presidente de la plata, los Señores oydores, Señor Visitador ${ }^{46}$, Señor Virrey, y lo que es mas el Rey Nuestro Señor y su consejo, como me escrive el Padre Antonio Ruiz en carta de Madrid de Enero del año pasado de 41, mandando por su real carta que en defensa natural de

\footnotetext{
${ }^{46}$ El Visitador General de la Real Audiencia de los Charcas era Don Juan de Palacios, del que se refiere el P. Boroa "que con universal aplauso de todos estados ha comenzado ya à exercitar su comision, desde el Puerto de Buenos Ayres á estas Gobernaciones por donde ha pasado con diligencia al Peru y por su mucha Cristiandad y zelo dei servicio de Vuestra Magestad y bien comun, (Cortesao, 1969, p. 302)
} 
gente tal se tomen las armas, y usen delas de fuego los Indios, que por ninguna ley les están prohibidas, aprobando lo que de parte de la Compañia se ha hecho y haze en esta parte en esta provincia, exhortando y animando personalmente a los Indios á su defensa por entender ser esta la voluntad de Dios Nuestro Señor, que la ha manifestado con mover a un mesmo tiempo á muchas personas graves de diversas provincias y reynos de España y las Indias, y del mesmo Brasil a escucharnos exhortandonos y animandonos á esta justa defensa y muy especial el Padre Nicolas Mastrilo Duran Provincial del Peru ${ }^{47}$, y el Padre Francisco Lupercio de Zubrano Provincial desta provincia del Paraguay ${ }^{48}$, viendo por los ojos aquella nueva iglesia de Xcristpo de las provincias del Paraná y Vruguay parte muy preciosa de la vniversal por la fe y loables costumbres de aquellos indios, y culto y veneracion, que hacen á su Criador y Redemptor, no solo aprobó este modo de defensa pero procu [270] curó su perfeccion y augmento, viendo ser precisamente necesario para su conservacion y sabiendo de cierto por informacion juridica que hizo como aun estavan todos aquellos montes sembrados de enemigo, juzgó esta guerra defensiva que alli se haze, por justa y santa, y la asistencia de los Padres a ella reusharia.

Pues en esta Santa y justa defensa y aun obligatoria fue muerto por religioso sacerdote, y zeloso y vigilante Pastor con vniversal sentimiento de todos los buenos y en especial de aquellas provincias del Vruguay y Paraná que hizieron extremos de dolor, del Señor Don Juan de Lizarazo ${ }^{49}$ y aquella Real Audiencia del Señor Conde de Chinchon Virrey del Peru ${ }^{50}$ que escrivió a su Magestad con grandeza, pretura sobre el caso y ultimamente su Magestad Catolica quando lo supo, y de su real Consejo de Indias, que sintió mal de la remision del Governador del Paraguay, que se halló presente y de sus soldados sino tambien el Señor Presidente y real Audiencia, y las demostraciones de su Magestad hubieran sido yguales al sentimiento de tan sacrílega maldad, a no haverlo impedido el alzamiento de Portugal y Brasil, con que echaron el sello a sus maldades, y hizieron creyble solo lo que se ha dicho dellos, que por su exorbitancia ponía dificultad a su creencia.

Y siendo esto, assi como lo es, ceden lenguas malevolas de vomitar su veneno, y de picar como serpientes la venerable y religiosa memoria del Padre Diego de Alfaro, varon verdaderamente fuerte pues tan animosamente se careó con la muerte y la venció, docto en todas ciencias y prudente, varon verdaderamente justo, casto, con vn rcato y pureza Angelica, misericordioso, y no solo caritativo, pero victima de la caridad, pues por amor de Dios, y de sus ovejas ofreció su sangre y su vida en sacrificio liberalmente á su Criador coronado su Santa vida con honrosa y gloriosa muerte, preciosa a ojos de

47 El napolitano Nicolás Mastrilli Durán (1568-1653), misionero y superior, fue procurador del Perú (1618-1622) y luego provincial del Paraguay (1623-1629), cuando se interiorizó de los sucesos de las misiones del Guayrá. Regresó luego a Lima donde fue provincial en dos oportunidades (1630-1634 y 1639-1644)

${ }^{48}$ El P. Francisco (1589-1667) como el P. Mastrilli, también fue provincial de las dos provincias, la del Paraguay (1640-1645) y la del Perú (1645-1649). En Córdoba le tocó lidiar con el obispo Cárdenas por la dudosa ilegitimidad de su nombramiento y sobre todo porque no solo estaba de acuerdo con el servicio personal sino tenía un plan para entregar las misiones jesuíticas al clero secular. Pero no pudo con el P. Zurbano.

${ }^{49}$ Don Juan de Lizarasu, era Presidente de la Real Audiencia de Charcas, que al decir del P. Boroa actuaba "con zelo, fidelidad y vigilancia açude siempre à Ias cosas de Vuestro Real servicio" (Cortesão, 1969, p. 302).

${ }^{50}$ Se refiere a Luis Jerónimo Fernández de Cabrera y Bobadilla (1589-1647) cuarto conde de Chinchón, vierrey del Perú entre 1629 y 1239 
Dios, Pretiosa in conspectu Domini mors Sanctorum eius ${ }^{51}$, tal mela dé el Señor y Vuestra Paternidad mela alcanza en sus Santos sacrificios y oraciones, que aunque entendi ser mas breve, y no pasar de medio pliego, la raçon mis obligaciones y amor al Padre Diego de Alfaro no han podido contener la pluma.

Cordova, 18 de Enero de 1644

Hijo indigno de Vuestro Padre

Diego de Boroa

\section{Referencias}

Alegambe, P. (1657). Mortes illvstres et gesta eorum de Societate Iesv... Roma: Ex Typografhia Varesij.

Baptista, J y Carman, P. (2001). Díaz Taño, Francisco. Misionero, superior. En: O`Neill SJ, C. y Domínguez SJ, J. M. Diccionario histórico de la Compañía de Jesús. Biográfico-Temático. Tomo 2. Roma/Madrid: Institutum Historicum $\mathrm{Si} /$ Universidad Pontificia Comillas.

Bullarium Romanum (1769). Bullarum diplomatum et privilegiorum sanctorum Romanorum pontificum taurinensis edition. Augustae Taurinorum: A. Vecco et sochs editoribus, tomo 14.

Cortesão, J. (1969). Manuscritos da Coleção de Angelis. Jesuítas e bandeirantes no Tape (1615-1641). Río de Janeiro: Biblioteca Nacional.

De Smet, S. (2001). Lessius (Leys), Leonardus (Lenaert). Teólogo, controversista, escritor ascético. En: O`Neill SJ, C. y Domínguez SJ, J. M. Diccionario histórico de la Compañía de Jesús. Biográfico-Temático. Tomo 2. Roma/Madrid: Institutum Historicum Si/Universidad Pontificia Comillas.

Del Techo, SJ, N. [1673] (2005). Historia de la Provincia del Paraguay de la Compañía de Jesús. Asunción: Centro de Estudios Paraguayos “Antonio Guasch/Fondec

Donnelly, J. O. (2001). Toledo Francisco de. Teólogo, diplomático, cardenal. En: O`Neill SJ, C. y Domínguez SJ, J. M. Diccionario histórico de la Compañía de Jesús. Biográfico-Temático. Tomo 4. Roma/Madrid: Institutum Historicum Si/Universidad Pontificia Comillas.

Ellis, M. (1970). A presença de Rapôso Tavares na expansão paulista. Revista do Instituto de Estudos Brasileiros, São Paulo, n. 9, p. 23-61, 1970.

Freisleben, Christophorus Henricus (1746). Corpus iuris canonici academucum, ad modum Christoph. Henr. Freisleben alias Ferromontani; emendatum et notis $P$. Lancellotti. Coloniae Munatianae: impensis J. R. Thurniss.

Furlong, SJ, G. (1962). Misiones y sus pueblos de guaranies. Buenos Aires.

${ }^{51}$ Psalmi 115:15 Biblia Sacra Vulgata. 
Gacto, E. (1992). Censura política e Inquisición: la Historia Pontifical de Gonzalo de Illescas, Revista de la Inquisición 2, Madrid.

Hernández SJ, P. (1913). Organización social de las doctrinas guaranies de la Compañía de Jesús. Tomo 1. Barcelona: Gustavo Gili ed.

Leonhardt SJ, C. (1929). Documentos para la Historia Argentina Tomo XX. Iglesia. Cartas Anuas de la Provincia del Paraguay, Chile y Tucumán de la Compañía de Jesús. Buenos Aires Facultad de Filosofía y Letras.

Lessio, L. (1605). De justitia et jure caeterisque virtutibus cardinalibus. Lovania: Ex oficina J. Masii.

Lovay, S. M. (2016. La autobiografía del P. Boroa. IHS. Antiguos Jesuitas en Iberoamérica. 4 (1). Enero/Junio, pp. 118-129.

Maeder. E.J.A. (1984). Cartas Anuas de la Provincia del Paraguay 1637-1639. Buenos Aires: Fundación para la educación, la ciencia y la cultura.

Nieremberg, I. E. (1647). Vidas exemplares y venerables memorias de algunos claros varones de la Compañía de Jesús de los quales este Tomo Qvuarto... Madrid: Por Alonso de Paredes.

Page, C. A. (2017). La biografía del jesuita Marcial de Lorenzana, precursor de las misiones del Paraguay, escrita por el P. Diego de Boroa. Córdoba: CIECSCONICET/UNC y Báez ediciones.

Page, L. (2016). La Carta de edificación del P. Alonso D’Aragona escrita por el P. Diego de Boroa. IHS. Antiguos Jesuitas en Iberoamérica. 4 (1). Enero/Junio, pp. 130-147.

Pérez Alonso, M. I. (2001). Alfaro, Diego de. Misionero, víctima de la violencia. En: O`Neill SJ, C. y Domínguez SJ, J. M. Diccionario histórico de la Compañía de Jesús. Biográfico-Temático. Tomo 1. Roma/Madrid: Institutum Historicum $\mathrm{Si} /$ Universidad Pontificia Comillas.

Redden, A. (2012). Las buenas personas no les queda más que el dolor y el gemido: la violencia del martirio y la violencia del mártir en las fronteras de Nueva España y Paraguay. En: Zazueta Manjarrez, J.C. y López Castillo, G. La religión y los jesuitas en el noroeste novohispano. Culiacán: COLSIN. pp. 101-28.

Redden, A. (2016). Priestly Violence, Martyrdom, and Jesuits: The Case of Diego de Alfaro, S.J. (Paraguay 1639). En: Exploring Jesuit Distinctiveness: Interdisciplinary Perspectives on Ways of Proceeding within the Society of Jesus. Brill, Boston / Leiden, 81 - 113.

Sommervogel SJ, C. (1895). Bibliothéque de la Compagnie de Jésus. T VII, Bruselas/Paris: Oscar Schepens/Alphose Picard.

Storni SI, H. (1980). Catálogo de los jesuitas de la provincia del Paraguay (Cuenca del Plata) 1585-1768. Roma: Institutum Historicum S.I.

Tanner SI, M. (1675). Societas Jesu usque as sanguinis et vitce profusionem militans, in Europa, Africa, Asia, et America, contra gentiles, mahometanos, judceos, hareticos, impíos, pro Deo, fide ecclesia, pietate. Sive vita et mors eorum. Praga: Typis Universitatis Carolo-Ferdinandæ. 
Terreros y Pando, E. de (1788). Diccionario castellano con las voces de ciencias y artes y sus correspondientes en las tres lenguas francesa, latina e italiana. Tomo 3. Madrid: en la imprenta de la viuda de Ibarra, hijos y compañía.

Toleti SJ, F. (1600). Summae. De Sacerdotum Instructione libri VII Quibus omnis Christiani officii ratio explicatur. Opus cum omnibus tum Ecclesiasticis \& in primis Pastoribvs pernecessarium, nunc postremo plus... París, ex officinal J. Belleri. 